\title{
M-health Applied to Vaccinal Support: A review Integrative
}

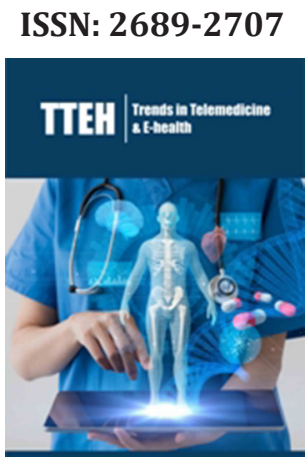

*Corresponding author: Agnes Altmann, Department of Health Sciences, Brazil

Submission: 海 November 29, 2019

Published: 洫February 28, 2020

Volume 2 - Issue 3

How to cite this article: Agnes Altmann*, Mellina Terres, Sílvio César Cazella. M-health Applied to Vaccinal Support: A review Integrative. Trends Telemed E-Health 2(3). TTEH.000536.2020. DOI: 10.31031/TTEH.2020.02.000536

Copyright@ Agnes Altmann, This article is distributed under the terms of the Creative Commons Attribution 4.0 International License, which permits unrestricted use and redistribution provided that the original author and source are credited.

\author{
Agnes Altmann*, Mellina Terres and Sílvio César Cazella \\ Department of Health Sciences, Brazil
}

\begin{abstract}
The use of mobile applications, through smart phones, smartphones, has been considered by many to be the technological revolution of greatest repercussion in recent times. Compared to a handheld computer and with access to millions of applications, its main feature is unlimited mobility, accompanying its user at all times and in any place. In health, it is known that professionals are constantly moving outside of the institutions in which they work, so mobility is fundamental, which contributes to the interoperability of mobile technologies. This study aims to identify the research involving mobile technology applied to the vaccination being used. The methodology used is of the type integrative review of the literature. The final sample had 14 papers. The analysis of the results showed that the most addressed issue in the development of mobile applications for the area of health vaccination was the guidance and reminders of vaccines to users through the application. When looking at the focus of these applications, you'll find that the area most benefited by mobile computing research for vaccination has been education and user orientation. It was concluded with the review that the development of mobile vaccination applications linked to scientific research is of paramount importance because its content will be analyzed and tested by professionals who know the real needs of the end users
\end{abstract}

Keywords: Mobile applications; Vaccines; Health apps

\section{Introduction}

The World Health Organization (WHO) advocates universal vaccination as a means of prevention of numerous diseases as 19 million children worldwide are not vaccinated or need extra immunization. According to WHO, vaccination "Saves millions of lives" and is recognized worldwide as one of the most successful and efficient prevention and the lowest cost. According to data campaign foster equity and access to vaccinations, strengthen national immunization programs to reach populations with limited access to regular health services such as those on the outskirts urban, rural, border and indigenous communities, providing platform to raise awareness about the importance of immunization and maintain the topic on the political agenda [1]. Our vaccine coverage is still very heterogeneous, reflecting factors such as: great extent of our country, the lack of communication through an integrated system between the Health Care Units and the rework generated by the loss of vaccination cards. As well as lack of information, issues of accessibility and culture contribute to the reduction of adherents to health and should be worked out so as not to interfere so significantly with the vaccination coverage [2-5].

The development of new technologies, such as computerized registration systems vaccination with nominal data is essential for maintaining good quality [6-10], Computerized systems are useful for scheduling vaccinations, user identification, search for absenteeism and monitoring of coverage vaccination and adverse events following vaccination. Also, if related to other health and socio-demographic information systems, becomes a unique instrument for the planning and evaluation of public health actions, besides presenting information reliability, data accuracy and increased services provided by health professionals [9]. Computerized vaccine registration systems are an important tool for the increase and maintenance of vaccine coverage, generating information for data systems, and serve as reliable assessment tools for vaccine situation. The popularization of smart phones, smartphones, has been considered by many to be the most impacting technological revolution in recent times after the revolution caused by the Internet and social networks [1]. 
M-Health can be defined as the use of communication technologies and information for the provision and improvement of health services. The mobility of this tool provides conditions for continuous health control and assessment, shows a new model that encourages healthy behaviors and helps in management and selfmanagement prevention or chronic conditions, among many other applications. The main feature of mobile applications is breaking mobility limitation, ease of use, interoperability and accessibility $[2,4,7]$. Another relevant aspect is the personality that the equipment provides to its users, considering that the professional can use his personal device, which he is used to dealing with daily [3].In addition, it can enable professionals to achieve more precision and agility in their work [7].

This review is an integrative review and part of a larger project aimed at development of new mobile technology for the area of vaccination in Public Health. Also, the review study is critical in identifying the gaps to be researched on the subject. Thus, the object of the research was to identify the state of art of mobile vaccination applications in other countries for prevention health through vaccination.

\section{Materials and Method}

In the first stage, the problem was identified and the guiding questions of the (Figure 1)

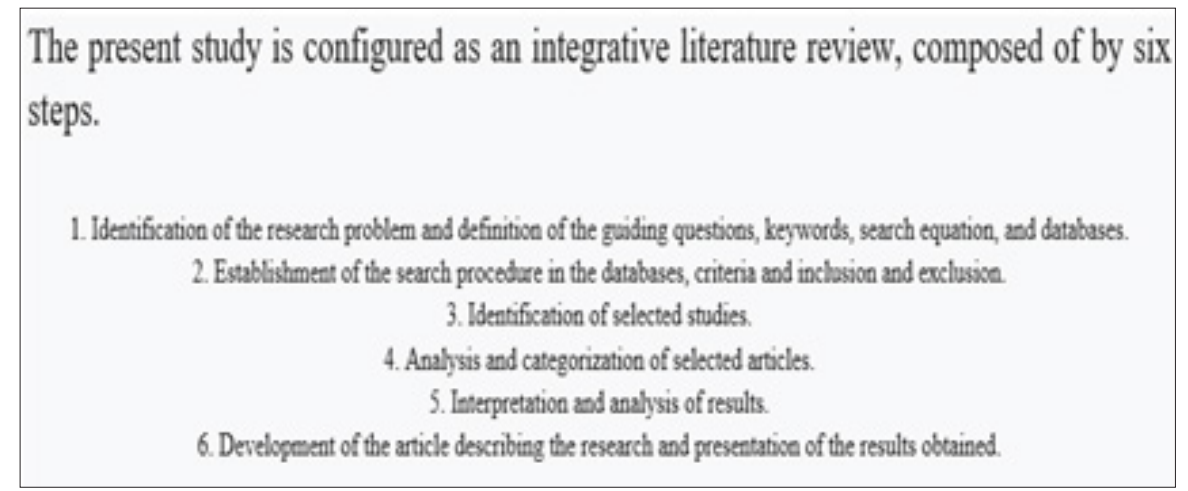

Figure 1: Steps of the integrative literature review.

A. How are mobile apps being used to vaccination?

B. What features are being implemented in this type of application?

C. What application use can contribute to health research focused on vaccination? Which health professionals are benefiting from this kind of app? Following, the keywords "vaccine" were defined, "Mobile health", "apps" and "vaccination". After the search tests phase with the key words in the Capes journal platform, the following equation was defined: search: vaccines and "mobile app" / ("mobile" [tw] and "health [tw] or" mobile health "[tw] or "Apps" [tw] and ("vaccination" [mesh] or "vaccination" [tw]). We opted to perform the search database that returned a greater number of publications in the Capes search and that showed a greater relation with the researched theme. Thus, the following databases were defined: PubMed (Public Library of Medicine) and SciELO (Scientific Electronic Library Online). In the second stage, the criteria for inclusion and exclusion as described in Table 1.

Table 1: Step 2 of the integrative review: inclusion and exclusion criteria

\begin{tabular}{|c|c|}
\hline Inclusion Criteria & Exclusion Criteria \\
\hline Original Article & Systematic Review Article \\
\hline Journal Articles & Duplicate Articles \\
\hline Articles in English Language & Articles without open access \\
\hline Peer-reviewed journals & Subject out of search scope \\
\hline Articles open in full & Paid articles \\
\hline Articles published from January 2005 Public Health and Technology & Articles published before 2005. \\
\hline
\end{tabular}

After reading and analyzing 109 returned titles and abstracts, the following publications that had the potential to answer the guiding questions and addressed the inclusion and exclusion criteria. of the total publications found [11], remained for full reading. After careful analysis, it was observed that some references had the potential to answer the questions and were carefully analyzed. Subsequently, a thorough reading of the material was performed in full and extracted the concepts approached, comparing them and grouping them through the pre-established criteria [12-20]. 


\section{Identification of pre-selected and selected studies}

In this study, a total of 109 studies were found in the databases, of which 4 were from SciELO, 105 Portal portal PubMed. After the criteria of inclusion and exclusion resulted in 12 articles from Pubmed and 2 articles from Scielo. The selected works were summarized and classified according to the following criteria: year of publication, following distribution: 2018 (2), 2017 (5), 2016 (4), 2015 (1), 2014 (1) and 2013 (1); type of publication, being 14 articles, the remaining types were not used, such as: dissertation and course completion work [21].

\section{Result and Discussion}

After analyzing the data found, and using interpretive reading, emerged the following categories for mobile applications developed for health: "technology", "management" and "users".

\section{Technology}

Regarding the "technology" category, three publications were found: one developed an application to evaluate the use by health professional users and 21 others on an m-Health Pilot Study to promote HPV vaccination, 22 and the last, 23 bringing the contribution of the development of mobile applications as data from electronic records in order to increase information and reliability of yellow fever vaccines. In the study conducted in USA, 21 have been shown the requirements of the proposed assessment of the application in question, considering the features: functionality (which defines the capacity of the software providing functions that meet explicit and implicit needs); the reliability (ability of the software to maintain a specified performance level); usability (ability of the software to be understood, learned, operated and attractive to user); the efficiency (runtime and the resources involved); and the maintainability (ease of modification of the software, including both the functionality improvements or extensions for bug fixes, crashes or errors); in the work process of health professionals. It is also highlighted in which, in the evaluation of the characteristics of the software used, were obtained positive responses, as they were considered easily accessible and understandable, serving as a tool that assists the health manager in planning and decision-making on health staff in hospital institutions [22]. 20 Koreano22 study that addressed the contributions and limitations of a mobile app for HPV control, pointed out limitations such as: education, safety, privacy and open standards.

However, he pointed out several advantages, such as: farreaching information, behavior change, a low cost. Also, scalability, technological autonomy, adaptation of the software to local language and culture, stability and impact on service quality of health. Thus, the study showed that the application points to political conditions and technologies to collaborate and dialogue with the principles of health prevention, as well as contributing to increased immunization coverage and cancer eradication in women [23]. Finally, the last study done in Sweden, 23 on the contribution and limitations of the mobile app for the control of yellow fever, dealt with the evaluation of an electronic documentation system
- electronic registration, aiming at verify its technical quality and functional performance, based on the perception of computer specialists, nursing teaching assistants in order to identify possible technical failures and limitations for product improvements Final. Thus, according to the study, the developed system showed positive responses from some categories, such as reliability, suitability functional, usability, performance efficiency, compatibility, security, portability, providing answers to the assistance provided [23].

\section{Management}

Regarding the "Vaccination Management" category, four studies were elected which contemplated the use of mobile applications aimed at controlling the vaccination care. One of the selected studies, 24 deals with the idealization, execution and testing an app to seek continuous improvement of immunization coverage in Sichuan rural in China. In this app, doctors found it best to manage vaccines and with lower cost and time saving. However, it was difficult for doctors administer care to child patients who have left for other municipalities [24]. Another study 25 showing a practiceoriented device based on audience mapping, in this case measles and rubella in Kenya, aiming at vaccination with shorter campaign time. Like reported by the author, this app has been successfully used, including decreasing from 6 months to 4 weeks immunization coverage in the region [25]. Another study, 26 developed in Africa, made a vaccination app using SMS to remind and to guide health caregivers and the population on adherence to vaccination, in this case, the work was dedicated to the prevention of diseases with Focus on measles. This study resulted in decreased disease outbreak and increased vaccination coverage through post SMS reminders, waiting for vaccines and the dropout rate of African children [26]. Finally, the latest study [27] talks about the importance of bilingual (pan-free) mobile apps in helping to map provincial and territorial vaccines of immigrants in the Canada. This study showed that the use of vaccination applications assists in the disease control in the country and served as an instrument of adherence to vaccination campaigns across the country [27].

\section{Users}

In this category, seven publications were selected. One of the selected studies, 28 deals with the use of a mobile application to monitor vaccine coverage in the Pakistan. In this service, there are SMS messages directed to the user in order to inform you of the availability of vaccines and locations that are providing care. However, the problem of not receiving SMS by some due to internet failures and distance from large access centers [28]. Already in the study, 29 developed in Berlin, Germany, is the application of VaCcApp, which informs and guides users about vaccines, assists with reminders of family's immunization history, clarifies doubts regarding vaccines and health prevention, involves the family making them active agents in vaccine control of your kids. In addition, it motivates all users by assisting them with questions and next immunizations to be carried out [29]. The article, 30 conducted in Kenya in Africa, uses SMS to advise on vaccination campaigns and shows that they help significantly in coverage 
and punctuality Vaccine. Also, it was noted that were previously there was coverage of $85 \%$ of population, the other $15 \%$ coverage was achieved through the use of SMS to reminders to users and control [30]. Another study, 31 conducted in Italy show that Mobile interventions bring information to parents about vaccination and can be used to increase knowledge through the dissemination of evidence users, reliability in prevention and decision-making assistance regarding the practice of vaccination. Success in designing and implementing this system information to users can be seen as an outline for system of standardization and computerization of immunization control through the psychological empowerment, risk perception, attitude, confidence and recommendation [31]. Another study, 32 conducted in Nigeria on the African continent, developed a application for use on mobile phones to remind users about the immunization schedule, providing subsidies for increased immunization coverage, optimizing o Services for greater absorption of routine immunization. One question raised in this article, addresses the need for ongoing training for users, so that they know how to use the tool and with this, a greater adherence to vaccination campaigns [32]. Another selected study, 33 talks about the use of vaccination application in the polio campaign in South Sudan where they had 95\% immunization coverage in the country, using mobile technology. In this study, 34 an application was developed in Pune, India, to guide users about the influenza vaccination campaign. During this study, it was observed the decrease of time devoted to campaigns by health professionals, saving resources for the dissemination of the vaccination campaign, reduction of lags in health data management and analysis, improved data quality reported and fewer information errors [33-36].

\section{Conclusion}

In this study we presented the mobile health applications applied to vaccination identified in the scientific literature of several countries, according to the descriptors proposed. Based on the selected studies, the categories showed that Mobile applications have the functions not only of assisting professionals but also directly reach users. However, they need to be tested and evaluated to reduce constraints and increase contributions. Findings point to reduced number of works developed with this theme, considering the descriptors proposed, yet it is known that there has been growth over the years in relation to creation of mobile applications for use in vaccination. However, it is necessary that thematic scholars seek to standardize the descriptors in order to facilitate and provide a qualified search, thus allowing for greater visibility of the studies, it is also emphasized the importance of the dissemination and publication of these products.

In this study we presented the mobile health applications applied to vaccination identified in the scientific literature of several countries, according to the descriptors proposed. Based on the selected studies, the categories showed that Mobile applications have the functions not only of assisting professionals but also directly reach users. However, they need to be tested and evaluated to reduce constraints and increase contributions. Findings point to reduced number of works developed with this theme, considering the descriptors proposed, yet it is known that there has been growth over the years in relation to creation of mobile applications for use in vaccination. However, it is necessary that thematic scholars seek to standardize the descriptors in order to facilitate and provide a qualified search, thus allowing for greater visibility of the studies, it is also emphasized the importance of the dissemination and publication of these products. applications based on Scientific research is important because it directs the contents since they come from studies and analysis of professionals who know the real needs of users. Thus, it is understood that recognizing the needs of these users is essential for planning and implementing new consistent and appropriate manner, in accordance with the specific demands, tested in research and implemented in practice. For future work, it is suggested that, in addition to the applications that support professionals, it is necessary to develop more direct patient support applications. This will allow them to become more involved with aspects related to their own health, have access to information and, when necessary, receive remote support for selfcare and its treatment, acting with a self-management of health.

\section{References}

1. (2018) Pan American health organization Brasil. Vaccination week in the America.

2. (2016) Vaccines: the origins, importance and new debates about their use. Brasil.

3. https://www.unasus.gov.br/noticia/dobrou-o-numero-de-paisesqueatingiram-metas-de-imunizacao-desde-2000 Acessado 30/09/2018

4. Homma A, Martins RM, Leal MLF, Freire MS, Couto AR (2011) Update on vaccines, immunizations and technological innovation. Cienc Saude Coletiva 16(2): 445-458.

5. Domingues CMAS, Teixeira AMS (2013) Vaccine coverage and vaccinepreventable diseases in Brazil in the period 19822012: Advances and challenges of the national immunization program. Epidemiol Serv Saude 22(1): 9-27.

6. Waldman EA (2008) Round table: Social inequalities and vaccination coverage: use of household surveys. Rev Bras Epidemiol 11(Suppl 1): 129-132.

7. (2014) Community preventive services task force. Recommendation for use of immunization information systems to increase vaccination rates. J Public Health Manag Pract 21(3): 249-252.

8. Luhm KR, Cardoso MRA, Waldman EA (2011) Vaccination coverage among children under two years from the computerized immunization record in Curitiba PR. Rev Public Health 45(1): 90-98.

9. Luhm KR, Waldman EA (2009) Computerized immunization registration systems: A review focusing on child health. Epidemiol Serv Saude 18(1): 65-78.

10. Novick LF (2014) Immunization information systems. J Public Health Manag Pract.

11. Menezes JR (2011) InteliMed: An experience of developing a mobile medical diagnosis support system. Rev Bras de Comp Aplic 3(1): 30-42.

12. (2018) Education Portal Brazil. Brasil.

13. (2018) Court of accounts of the Brazil union. National immunization program. Audit and Performance Report, Brasil. 
14. Rocha PK, Prado ML, Wal ML, Carraro TE (2008) Care and technology: Approaches through the care model. Rev Bras Enferm 61(1): 113-116.

15. Araújo MVS, Alves F (2012) Use of mobile devices in health monitoring. I II scientific day of information systems (Jornascsi). Parnaíba-PI: Proceedings of the III Scientific Day of Information Systems 2012. Brasil.

16. Barone DAC, Figueiredo MC, Wink GL (2012) The impact of ICT use on health: Development and application of a mobile system in the strategic family health program. 2012 XXXVIII Latin American Computer Conference-CLEI. pp. 1-7.

17. Júnior AC (2006) Study and development of an application for hospitalhospital environments, considering the use of mobile devices using wireless communication networks. Joinville, Brazil.

18. Fernandes BMV (2011) SSVV Monitoring and Management System based on Mobile Devices.

19. Santos JA, Filho DP (1998) Scientific methodology. Sao Paulo: Futura.

20. Gil AC (2008) Methods and techniques of social research.

21. Bednarczyk RA, Frew PM, Salmon DA, Whitney E, Omer SB (2016) ReadyVax: A new mobile vaccine information app. Human Vaccines Immunotherapeutics 13(5): 1149-1154.

22. Lee HY, Koopmeiners JS, Hugh J, Raveis VH, Ahluwalia JS (2016) mHealth pilot study: Text messaging intervention to promote HPV vaccination. Am J Health Behav 40(1): 67-76.

23. Kumanan W, Atkinson KM, Bell CP (2016) Travel vaccines enter the digital age: Creating a virtual immunization record. Am J Trop Med Hyg 94(3): 485-488.

24. Chen L, Du X, Zhang L, Velthoven HV, Wu Q et al. (2016) Effectiveness of a smartphone app on improving immunization of children in rural sichuan province, China: A cluster randomized controlled trial. BMC Public Health 16: 909.

25. Ismail A, Tabu C, Onuekwusi T, Otieno SK, Ademba P, et al. (2017) Microplanning in a wide age range Measles Rubella (MR) campaign using mobile phone app, a case of Kenya, 2016. The Pan African Medical Journal 27(Supp 3): 16.

26. Manakong K (2017) SMS-reminder for vaccination in Africa: Research from published, unpublished and grey literature. The Pan African Medical Journal 27(Supp 3): 23.
27. Atkinson MPKM, Hui C, Ponka D, Manuel DG, Day D, et al. (2018) Immunization and technology among newcomers: A needs assessment survey for a vaccine-tracking app. Human Vaccines Immunotherapeutics. 14(7): 1660-1664.

28. Kazi AM, Murtaza A, Khoja S, Zaidia AK, Alia SA (2014) Monitoring polio supplementary immunization activities using an automated short text messaging system in Karachi, Pakistan. Bull World Health Organ 92(3): 220-225.

29. Seeber L, Conrad T, Hoppe C, Obermeier P, Chen X, et al. (2017) Educating parents about the vaccination status of their children: A user-centered mobile application. Preventive Medicine Reports 5: 241-250.

30. Gibson DG, Ochieng B, Kagucia EW, Were J, Hayford K, et al. (2017) Mobile phone-delivered reminders and incentives to improve childhood immunization coverage and timeliness in Kenya (M-SIMU): A cluster randomized controlled trial Lancet. Glob Health 5(4): e428-e438.

31. Fadda M, Galimberti E, Fiordelli M, Romanò L, Zanetti A, et al. (2017) Effectiveness of a smartphone app to increase parents' knowledge and empowerment in the MMR vaccination decision: A randomized controlled trial. Human Vaccines Immunotherapeutic 13(11): 25122521.

32. Akinrinade OT, Ajayi IO, Fatiregun AA, Isere EE, Yusuf BC, et al. (2018) Ownership of mobile phones and willingness to receive childhood immunization reminder messages among caregivers of infants in Ondo State, south-western Nigeria. S Afr J Child Health 12(3): 111-116.

33. Haskew J, Kenyi V, William J, Alum R, Puri A, et al. (2015) Use of mobile information technology during planning, implementation and evaluation of a polio campaign in South Sudan. Plos One 10(8): e0135362.

34. Giduthuri JG, Maire N, Joseph S, Kudale A, Schaetti C, et al. (2014) Developing and validating a tablet version of an illness explanatory model interview for a public health survey in Pune, India. Plos One 9(9): e107374.

35. Ganong LH (1987) Integrative reviews of nursing research. Res Nurs Health 10(1): 1-11.

36. Oliveira LM, Vergara CMAC, Sampaio HAC, Filho JEV (2018) mHealth technology in obesity prevention and control from the perspective of health literacy: Lisa Obesity. Debate Health 42(118).

For possible submissions Click below: 